\title{
ACCELERATING GROUND-TEST CYCLE TIME; THE SIX-MINUTE MODEL CHANGE AND OTHER VISIONS FOR THE 21ST CENTURY
}

\author{
Jerome T. Kegelman* \\ NASA Langley Research Center \\ Hampton, VA 23681
}

\begin{abstract}
$\underline{\text { Abstract }}$
The advantage of managing organizations to minimize product development cycle time has been well established. This paper provides an overview of the wind tunnel testing cycle time reduction activities at Langley Research Center (LaRC) and gives the status of several improvements in the wind tunnel productivity and cost reductions that have resulted from these activities. Processes have been examined and optimized. Metric data from monitoring processes provides guidance for investments in advanced technologies. The most promising technologies under implementation today include the use of formally designed experiments, a diverse array of quick disconnect technology and the judicious use of advanced electronic and information technologies.
\end{abstract}

\section{Introduction}

Over the past two decades, the manufacturing community in the United States has recognized that a significant competitive advantage is gained by significantly reducing product development time. As the time between product conception and its delivery to the market is reduced, the manufacturer's ability to respond and adapt to changing market demand is increased, while the costs of doing business decrease substantially. The advantages of rapid product development cycle time for adapting to a niche market or responding to changing consumer demand ahead of the competition are obvious. The cost savings of rapid product development far outweigh the additional cost for developing the infrastructure, processes and machinery.

\footnotetext{
*Head, Research Facilities Branch, Aero- and GasDynamics Division, Member AIAA.

Copyright (C) by the American Institute of Aeronautics and Astronautics, Inc. No copyright is asserted in the United States under Title 17, U. S. Code. The U. S. Government has a royalty-free license to exercise all rights under the copyright claimed herein for Government Purposes. All other rights are reserved by the copyright
owner.
}

Cycle time reductions of up to two orders of magnitude have resulted in corresponding reductions in inventories, work in process, labor costs, as well as facility overhead. Successes in the automotive and electronic industries, led by Japanese firms such as Toyota and Sony, provide ample evidence of the advantages of minimizing development cycle time to increase competitive advantage and decrease costs.

The aircraft manufacturing industry has been driven to follow suit with some success. However, inherent in the development cycle of any new or derivative aircraft are a series of wind tunnel test cycles. For consistency, the wind tunnel test cycle here is defined as the time between delivery of a set of loft lines to a model designer and delivery of wind tunnel test data. A typical new aircraft development will require several of these cycles, each currently lasting as long as one year. A series of these test cycles can contribute perhaps several years to the development time of a new aircraft.

The wind tunnel test cycle includes the test article or model design and fabrication time, the Model/Facility integration time, the wind tunnel test time and the data reduction and delivery time. Substantial advances have been made in reducing model design and fabrication time, notably led by the "Six Day Model Team" at the Boeing Commercial Aircraft Group.

The wind tunnel testing community has just recently begun to focus on substantially reducing the cycle time associated with wind tunnel testing. It can hardly be any advantage for a customer to provide a test article in six days if the nearest tunnel availability date for a high Reynolds number facility is eight to ten months down the road! Recent efforts at NASA Langley Research Center to reduce wind tunnel testing cycle time have been initiated. A few recent successes, along with plans for continued cycle time reduction, are the subject of this paper. 


\section{Background and History}

About four years ago, as a result of a major reorganization of the NASA Langley Research Center, significant changes began in the way wind tunnels were operated at the Center. The consolidation of wind tunnel operations in the Aero- and Gas-Dynamics Division (formerly the Aerodynamics Division) under one operations branch was undertaken to initiate a major cultural change. ${ }^{1}$ In particular this change was undertaken to improve customer satisfaction with wind tunnel operations and data quality. In addition, it was also believed that a centralized management of the tunnels could provide more emphasis on commitment to schedule, attention to data quality, improvements to productivity, and improvements to reliability of these facilities. By combining the operation of these facilities under one organization, improvements across all facilities could be accomplished by standardization and use of common tools and test techniques. Langley has also formed what is called the Wind Tunnel Enterprise (WTE), a virtual organization which includes the providers, the customers and the stakeholders for the wind tunnel activities at the center.

Following the reorganization, a set of goals were developed for the Research Facilities Branch (RFB), the organization responsible for the operations of most of the major facilities at LaRC. ${ }^{2}$ These goals were:

- Be customer driven, meeting negotiated customer expectations $100 \%$ of the time.

- Provide customers with data at required uncertainty level (no better/no worse).

- Operate based on sound business practices.

- Provide "world class" basic instrumentation set.

- Continuously improve test process.

- Provide data in a timely manner that fits customer development cycle.

- Continuously improve productivity and reduce cost of operating facilities.

The substantial effort focused on achieving these goals has had an enormous impact on the productivity of the facilities. Figure 1 illustrates the positive effect this effort has had on productivity, as measured by Polars per User Occupancy Hour, Cost per Polar, and Customer Satisfaction. User Occupancy Hours (UOH) are defined as the time from the start of model installation in the test section until the model is removed from the test section, less Scheduled and Unscheduled Downtime. (Appendix A includes a more complete list of the definitions of the LaRC metrics.) These data represent non-weighted averages for the National Transonic Facility, the Unitary Plan Wind Tunnel, the 16-Foot Transonic Tunnel, and the 14- by 22-Foot Subsonic Tunnel. Productivity has increased by a factor of 3 since 1994, while the cost per polar has decreased by nearly $60 \%$. These improvements have been made while the customer satisfaction index has increased from just over 3.5 to nearly 4.5 , using a scale from 1 to 5 .

\section{The Changing Paradigm}

For as long as anyone in the business today can remember, the mode of operation for wind tunnel testing has been for the providers of wind tunnel services to sell wind tunnel time and not wind tunnel results. The dilemma associated with selling wind tunnel time and not wind tunnel data, while measuring performance by counting data points, is illustrated in Figures 2 through 5. Figure 2 shows that the wind-on run hours has increased by a factor of 2.3 in the 16-Foot Transonic Tunnel since 1994. Figure 3 shows that the tunnel productivity as measured by the number of data points, has gone up by a factor of 5.1. Shown in Figure 4 are the number of tests per year from the years 1983-1997. In 1997, the tunnel produced over 5 times the data produced in 1994 (figure 5). Note that the number of tests per year shows no significant increase between the years 1994 and 1997, certainly not commensurate with the dramatic increases in productivity achieved in 1997. Clearly a great deal more data per test is being generated, yet no more tests per unit time are being completed. These results hold true for all of Langley's major wind tunnel facilities.

To move beyond this level of performance and shorten the duration of each test (or increase the number of tests), the paradigm of selling tunnel time and not tunnel results must change. Several promising technologies for changing this paradigm and substantially decreasing the test cycle time will be addressed in section IV.

\section{Cycle Time Reduction as a Goal within NASA}

It has been well established that the best practice for changing an organization to one where 
minimizing cycle time is of the highest priority is to ensure that all levels of the organization support this objective. ${ }^{3}$ It is clear that NASA, as an agency, has endorsed reducing aircraft development cycle time from the top levels at Headquarters down through the facilities responsible for tunnel operations at the individual Aeronautics Centers.

In the Agency's Strategic Plan ${ }^{3}$ there are four strategic enterprises, one of which is the Aeronautics and Space Transportation Enterprise. This enterprise has three major technology goals supported by ten enabling technology objectives. The second of these three goals is called "Revolutionary Technology Leaps" and is defined as:

"Revolutionize air travel and the way in which aircraft are designed, built and operated."

Under this goal the enabling technology objective is:

"To provide next generation design tools and experimental aircraft to increase design confidence, and cut the design cycle time for aircraft in half."

The Agency has established the Wind Tunnel Facility Group Director's Office (WTFGDO) which is responsible for the coordinated and efficient operations of the Agency's wind tunnel facilities in support of its programs. The WTFGDO has strongly endorsed a six-fold reduction in the wind tunnel test cycle time in order to help meet the overall reduction of aircraft development by a factor of two. The WTFGDO has sponsored two multiday workshops on cycle time reduction involving the organizations responsible for the Agency's major wind tunnel operations at Ames Research Center, Lewis Research Center, and Langley Research Center. Also included were the operators of the major wind tunnel facilities at the Air Force Material Command's Arnold Engineering Development Center. This group, representing all of the nation's large wind tunnel facilities, has developed consensus agreement on aggressive goals for reducing the time to conduct wind tunnel tests. A significant outcome of these workshops is the common recognition that all suppliers of wind tunnel services are actively pursuing similar cycle time reduction goals, and opportunities exist for leveraging technologies developed at these various sites for the benefit of all.

The Wind Tunnel Enterprise at Langley Research Center has now placed wind tunnel test cycle time reduction as one of its highest priorities, along with developing a credible and defensible Data Quality Assurance Program and unparalleled customer satisfaction. A mission statement, measures of performance, and goals were developed. The mission of the WTE is to:

"Provide reliable, accurate research information to the aeronautical community in a timely manner. To accomplish this requires a focus on increasing productivity, cost effective operations, technical support that adds value, and the development of new facility capability and test techniques."

In recognition of the dilemma noted above, where productivity has been quantified in terms of data acquisition rate, with high data volume as the goal and not results, the goals of the WTE have been re-examined. The initial set of goals was:

- Accuracy - Better than 0.0001 in drag coefficient

- Timeliness - Final data the same day

- Cost Effectiveness - 30\% decrease

- Value added support - customer confidence

- Reliability - 100 percent achievement of schedule commitments

- Productivity - 600 percent increase in Polars/hour

While the outcome of the activities of the WTE focused on meeting these goals has been to accelerate the accomplishment of this set of goals, test cycle time has not been reduced in proportion to the increases in productivity. In July of 1997, the WTE revisited these goals and developed a more comprehensive set of goals, consistent with the Agency's Strategic Plan. The complete set of revised goals are included in the Appendix A. The technical goals addressing cycle time reduction are:

\section{Technical Goals}

By 2002, the WTE provides world class subsonic, transonic, and supersonic test capability in support of NASA's goals for Global Civil Aviation, Access to Space, and Revolutionary Technology Leaps.

By 2000, the WTE provides fast, low cost, concept screening test capability across the Mach range $(0<M<20)$ to support the development of the next generation commercial and military aircraft and space launch vehicles.

The WTE fully integrates advanced wind tunnel testing into the next generation aircraft design processes by providing: 
- an order of magnitude reduction in complete wind tunnel test cycle time by 2002 and two orders of magnitude reduction by 2010

- virtual participation by test team for entire test cycle

The benefits of undertaking a systematic, broad and multi-disciplinary approach to cycle time reduction has been well established throughout the manufacturing industries. ${ }^{4,5}$ The effort should permeate all layers of management from the shop floor to the Division Offices responsible for tunnel operations. Fortunately, sound methodologies have been established for reducing cycle time, which will not be repeated here. A brief outline of what has been done and what is planned follows:

\section{I: Establish and Understand the Process}

A small team was formed in 1996 to study and clarify the test process in use at LaRC. This team has developed a detailed structure for the testing process for the Aero- and Gas-Dynamics Division wind tunnels. This process, illustrated in figure 6, accounts for all activities in the testing process from initial request for test time by the customer to delivery of the final data and test close-out. ${ }^{2}$ Each step of the process is being examined to reduce time, to reduce resource requirements, and to improve customer satisfaction. For example, all facilities now use an electronic, web-based test request process, a standard test plan format, and standardized pre-test and post-test meeting agendas. Standard procedures have been developed for most routine test activities, including assembly and verification of joints involving tapers and keys, set up and use of the Balance Dynamic Display Units used in all facilities, and calibration and installation of accelerometer type model attitude measurement systems.

The examination of the required documentation of the test process has led to substantial streamlining efforts, which includes the recent introduction of an automated test plan management system. This system serves to keep all members of the test team up to date and involved in the plan's development. It tracks relevant information in databases, tracks and provides automatic notification of due dates and action items and provides automatic setup and tracking of the test execution at the tunnel. This system eliminates the need for anyone in the test planning process to enter information more than once. For example, it was found that the test project engineer had to enter the wing pressure tap position as many as 5 times in various formats during the preparation for a test plan. Now all information is entered only once, with provisions for corrections. The infrastructure has been put in place to allow the test plan to be iterated between the customer and the test engineer, remotely and asynchronously.

The test plan management system provides the tunnel operators with significantly enhanced access to all information needed to efficiently conduct wind tunnel tests. The test plan management system will also provide the customer with "real time" access to all information about the test and the research results from the test.

The processes have been examined for the model design and fabrication, and efforts are now underway to extend the test plan management system to cover the model planning process as well. It should be noted that there are other related processes that accompany a test such as financial and business processes for funding a test, as well as the procurement and contract processes for supporting tests. While much less has been done for these processes, efforts are underway to streamline all processes associated with wind tunnel testing.

\section{II: Measure Each Step}

Measures of performance and goals were developed to determine progress towards accomplishment of the mission of the WTE. To monitor these metrics required that each facility put in place a system to gather the data. Prior to the formation of the RFB, this data gathering was sporadic at best, except in the National Transonic Facility, where detailed data on facility productivity, downtime, etc. has been kept since the facility first came on line. ${ }^{2}$ Since the formation of the RFB and the initiation of the WTE, all facilities are routinely gathering productivity data. When fully configured, the test planning management system will track the following measures of performance:

1. Operational hours

2. Data per occupancy hour

3. Cost per data unit

4. Maintenance cost

5. Data accuracy, quality, and uncertainty

6. Plan to actual

7. Workforce per facility 


\section{Time to deliver data}

9. Facility downtime

10. Model installation time

Data tracked in this manner provide key insight as to where we stand to gain the greatest improvements in test cycle time. Figure 7 illustrates how the activity at a wind tunnel is typically proportioned. The major learning from these data is that nearly $50 \%$ of the activity at a facility is spent on the test article, either with model installation or with the configuration changes. The tunnel actually runs only $25-30 \%$ of the time! This eye-opening realization has led to the focus on very rapid model changes; i.e., 6minute model changes. The author had set the goal of 6 minutes before learning of the industry standard practice for large facility utilization. The notion of a 6-minute model change is often met with disbelief, especially where configuration changes can now take an entire shift and complete model installations can take as much as a week. As difficult as it is for wind tunnel veterans to accept the notion of a 6-minute model change, industry-wide 'best practices' would suggest any major machinery changeover should take less than

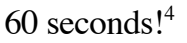

\section{Educate and Train}

The WTE has developed a set of cultural goals which address a critical element in any cycle time management plan. The goal is :

By 1998, the WTE creates a culture of excellence in wind tunnel technology and operations through creation of a "university" type environment which:

trains all workers in order to

- sustain and grow all wind tunnel skills

- provide repository of all our wind tunnel knowledge

- continually develop all technical staff skills

conducts research/development of

- test technology

- new testing capability

A curriculum including the basic principles of cycle time management, based primarily on the methods found in references 4 and 5, will be offered to all WTE participants. All facility managers and supporting supervisors will be trained in these methods.

\section{Focus on the Bottle Necks}

It has proved beneficial to have MultiDisciplinary Working Groups study the test planning and the model design and fabrication process. Teams are now being formed to address all remaining processes associated with tunnel testing. Each team is to include membership from all disciplines affected by the process, such as tunnel technicians, test engineers, management, procurement and those responsible for resource allocation.

A substantial focus of this re-engineering effort is to identify barriers to accomplishing tasks in the shortest possible time. These bottlenecks may be facility hardware related, or there may be procedural, organizational or cultural barriers that are hindering the accomplishment of the desired goals. The task at hand is to identify and eliminate them one by one. Three of the more promising areas of focus are addressed below.

\section{Use Formally Designed Experiments}

The Langley Research Center wind tunnel community is considering formally designed experiments as an alternative to the high-volume data collection strategy currently followed by the aerospace community at the LaRC tunnels and elsewhere. ${ }^{6}$ As mentioned above, productivity has been traditionally quantified at most major wind tunnel facilities in terms of data acquisition rate, with high data volume as the goal. However, since tunnel schedules are extraordinarily full, with lead times of up to two years, it is a natural tendency for the wind tunnel customer to have a long list of test conditions in hand upon arrival. Customers are driven to use a strategy of acquiring not only the highest priority data, but also lower priority data since the next testing opportunity may well be two years away! Since the prevailing wisdom has been to sell tunnel time by 8 -hour shifts, the customer will use every shift allotted for each test, regardless of the amount of data collected. Furthermore, the final results of many tests often rely on only a subset of the data acquired in a given test, suggesting that certain efficiencies can be realized by a more rigorous pre-test focus on the specific objectives and the resources required to achieve them.

Designed experiments seek to identify in pretest planning those specific questions that are to be answered by the wind tunnel test, and then to 
quantify the minimum resources required to answer those questions. This consistently leads to smaller resource requirements than in current tunnel testing procedures.

Extreme care must be given to the formulation of the test objective, so that the end of the test is not determined by the expiration of test time, as has been our tradition, but by the accomplishment of a quantified set of results! While a test objective is always given in each and every test plan at LaRC, these are not always developed to quantitatively indicate what is to be accomplished. A typical objective statement today might read as follows:

Perform high speed force and moment testing on configuration XYZ to examine stability and control characteristics.

Whereas a more appropriate objective statement would be as follows:

Develop an analytical model of the stability axis coefficients of roll moment and yaw moment for configuration $X Y Z$ as a function of angle of attack from $-4^{\circ}$ to $+20^{\circ}$ and side slip from $-8^{\circ}$ to $+8^{\circ}$ at a constant Reynolds number per foot of $4 \times 10^{6}$ and at Mach Numbers of 2.4 and 2.7

Ensure that there will be a probability of at least $90 \%$ of resolving a change in roll as small as \pm 0.0001 and yaw of \pm 0.0002 .

There will be at least a $95 \%$ probability that the coefficients predicted by these models will not differ from the true population means by more than these amounts.

Unless the test objective is defined with sufficient detail, accompanied by the level of confidence required for the results, the completion of the test is not defined.

Four designed experiments were conducted in LaRC wind tunnels in 1997, each time comparing results with those obtained using conventional methods. The same or better technical results were achieved with a total of over $80 \%$ fewer data points in tests at the Unitary Plan Wind Tunnel, the 16Foot Transonic Tunnel, and 14- by 22-Foot Subsonic Tunnel, on various wing-body-tail configurations and an X-33 single-stage-to-orbit technology demonstrator model. In these tests there were corresponding reductions in required wind-on minutes and associated costs of consumables. The average savings are illustrated in figure 8. While wind-on minutes comprise only a portion of the entire test cycle and these results reflect only a limited number of trial cases, formal methods of experiment design appear to have the potential for significant resource savings in wind tunnel testing.

\section{Eliminate Time Consuming Tasks}

Pre-test investment in technology and processes that substantially reduce the configuration change time (recall figure 7) can help achieve the goal of accomplishing the test in minimum time. The notion of using quick disconnects and standard interfaces in tunnel testing has been around for decades. However, in the past, minimizing cycle time was not as high a focus as it is today, and facilities have become accustomed to conducting business using the same methods that have been used for years. The bundle of very fine wires attached to strain gauge balances which must be fished through the sting and out of the tunnel with each balance change serves as an example of using methodology from the 1950's in tunnels today! LaRC has switched most of its balance inventory over to using a small standard connector attached to the balance to eliminate this problem.

LaRC is currently developing a standard model/balance/sting interface hardware for use in the Unitary Plan Wind Tunnel, the 16-Foot Transonic Tunnel, and the Low Turbulence Pressure Tunnel, which often run the same model through each facility to cover a wide Mach number range. While this project is in its infancy, it is similar to and will be coordinated with an effort at Ames Research Center, to avoid a duplication of effort and hopefully extend the number of facilities using common interfaces.

While the idea of quick disconnects is not unique to LaRC facilities, each facility presents a unique set of challenges with respect to rapid model changes, and cryogenic tunnel testing can be one of the most challenging.

In anticipation of a series of tests planned for BCAG on the W50, MD-11, and MD-XX last year, it was deemed advantageous to minimize the amount of time spent changing over wings from the W50 to the MD-11. Each wing had several hundred pressure taps which had to be connected to the Electronically Scanned Pressure (ESP) units with each wing change. In addition, a second W50 configuration was to be done without the wing pressures included for a force and moment test. 
A set of quick disconnects (see figure 9) suitable for cryogenic use were designed with a Grafoil seal, as opposed to Neoprene, that are found in commercially available disconnects. The principal challenge was to be able to seal under cryogenic conditions, whereas the commercially available disconnect design tested unsuccessfully cryogenically. These disconnects were also designed with the 48 port configuration to match the ESP modules. The quick disconnects were also to be used with blanking caps used to "plug" the pressure tubes for force and moment tests.

A total of 5 shifts were estimated to complete the hook-up the "old way" but the wing change was accomplished in 3 shifts using the quick disconnects. The actual time saved was about 2 shifts, representing a $40 \%$ reduction on the first goaround with these designs. This change included filling and sanding the model to be ready for test. The first attempt was not without some difficulties with the disconnects; notably, it was troublesome tracking specific tubes which had come loose because of the tubing having limited flexibility while it was constrained in the connector. Also, the choice of a random hook-up caused some problems in the beginning which, in the future, will be considerably improved. The "plugging" of the tubes was accomplished literally in minutes, rather than a half a shift to a shift. This activity illustrates a cycle time reduction of over two orders of magnitude.

In the future, it is planned to use this design or an alternate for the ESP's in the tunnel's wall pressure system to ease the replacement of modules and for future wings such as the Boeing 777 model to be tested in FY98. The customer deemed the connectors successful and would recommend them for any similar test program like the W50/MD-11 with a common fuselage configuration. The patent for the design is being reviewed by a commercial vendor; however, the Cryogenic application is unique to the few cryogenic tunnels in the world, making it difficult to justify its commercial value.

A substantial effort was initiated in 1996 to revolutionize the model instrumentation hardware for typical wind tunnel tests. Advances in the electronics industry over the last decade allow miniaturized electronic systems to be customized for specific applications at relatively low cost. An effort is in progress to evaluate and implement, for wind tunnel use, such technology that is now commonplace in such devices as credit-card sized digital cell phones. The objectives are to identify and implement the most likely and beneficial instrumentation technologies that will provide a radical improvement in model installation cycle time. It requires the design and fabrication of a prototype model with an on-board integral instrumentation system, which allows for both conventional and advanced micro-electro-mechanical (MEMS) sensors. This "plug and play" model will include an Application Specific Integrated Circuit (ASIC) based data system and wireless or fiber optic data transmission system, thus eliminating all instrumentation hook-up in the tunnel.

A block diagram of the system under development is shown in figure 10. The scope of the project includes the integration of MEMS type sensors and ASIC interfacing circuits into the wind tunnel model during design and fabrication. Development is underway for in-model data system electronic circuits using ASIC technology and a virtual wire data transfer system that will transfer a composite data stream from the wind tunnel model instrumentation system to the control room data acquisition system. University and industry partners are involved in this program. The plan is to minimize, or eliminate, most if not all of the instrumentation cabling between the model and the sting, allowing very rapid model installations.

Accomplishments over the last year include a preliminary review of candidate commercially available hardware technology for the Telemetry Systems using Radio Frequency (RF), Infrared (IR), Fiber Optics, and Ethernet communications technology. To evaluate the technology in the field, tests were conducted in the 16-Foot Transonic Tunnel (see figure 11). Results for this evaluation, shown in figure 12, indicate Fiber optics and 100 BT Ethernet meet the required data rate of 25 mbits/sec. RF and IR are applicable to meet data rates lower than 1 and $10 \mathrm{mbits} / \mathrm{sec}$, respectively. The RF data rate was found to be $0.65 \mathrm{mbits} / \mathrm{sec}$, while the IR data rate and 10BT data rate were found to be 8.5 and $8.6 \mathrm{mbits} / \mathrm{sec}$, respectively.

The definition of the on-board data system requirements for force balance, AOA, pressure sensors, and shear stress sensors was completed this year, including electronic modules for the Sensor/ Driver, Data System, and Controller Systems. The design of a Printed Circuit Board (PCB) version for the on-board system is in progress. The Center has established an electronic circuits design automation capability to develop cost effective application specific integrated circuits. 


\section{Closing Remarks}

The NASA Langley Research Center is continuing an aggressive program to re-engineer the way wind tunnel testing is accomplished. Reduction of test cycle time has been elevated to the highest priority, with the goal of radically accelerating the test cycle. A comprehensive approach to cycle time reduction is being systematically carried out, in which every aspect of the test process is being driven towards minimizing the time for each step. Metrics are being continuously acquired which serve to guide the investments in process improvements as well as evaluate progress. The most promising technologies under implementation today include the use of formally designed experiments, a diverse array of quick disconnect technology and the judicious use of advanced electronic and information technologies.

The new goals for the LaRC Wind Tunnel Enterprise will provide focused direction for tomorrow, while the momentum being developed today gives promise that they will be met and exceeded in the foreseeable future.

\section{$\underline{\text { Acknowledgments }}$}

This paper should be considered a report on the efforts of many individuals at LaRC, although responsibility for any inaccuracies in the presentation is mine alone. I especially want to acknowledge the essential contributions of Dr. Richard DeLoach, Dr. Seun Kahng, Mr. William Tomek, Mr. Daniel Cler, and Mr. Elwood Putnam. I also want to acknowledge the contributions of the LaRC Navigation Center and RFB staff, and the staff of the many other organizations at LaRC supporting the Aero- and Gas-Dynamics Division and the wind tunnel re-engineering effort.

\section{$\underline{\text { References }}$}

${ }^{1}$ Putnam, Lawrence E., "Re-Engineering Wind Tunnel Testing at NASA Langley Research Center," Symposium of the International Test and Evaluation Association, Huntsville, AL, October 2-5, 1995.

${ }^{2}$ Putnam, Lawrence E., "Wind Tunnel Productivity Status and Improvement Activities at NASA Langley Research Center," AIAA Paper No. 96-2260, 19th AIAA Advanced Measurement and
Ground Testing Technology Conference, New Orleans, LA, June 17-20, 1996.

${ }^{3}$ NASA Policy Directive (NPD)-1000.1 "NASA Strategic Plan, 1998," Available through NASA Headquarters, 300 E Street, S.W., Washington DC 20546 Also available at: http://www.hq.nasa.gov/office/nsp/NSPTOC.html

${ }^{4}$ Northey, Patrick and Southway, Nigel, "Cycle Time Management: The Fast Track to Time-Based Productivity Improvement," Productivity Press, May, 1994.

${ }^{5}$ Goldratt, Eliyahu M. and Cox, Jeff, "The Goal: A Process of Ongoing Improvement," North River Press, Aug, 1994.

${ }^{6}$ DeLoach, Richard, “Applications of Modern Experimental Design to Wind Tunnel Testing at NASA Langley Research Center," AIAA Paper No. 98-0713, 36th Aerospace Sciences Meeting and Exhibit, Reno, NV, Jan 12-15, 1998.

\section{Appendix A: Metric Definitions}

The metrics used in the Wind Tunnel Enterprise at LaRC are defined as follows:

Total Occupancy Hours $(\mathrm{TOH})=($ Hours facility is open each day) $x$ (52 weeks $x \quad 5$ days/week) - Holidays

Available Occupancy Hours $(\mathrm{AOH})=\mathrm{TOH}-$ (Scheduled Downtime)

where Scheduled-Downtime includes, for example, time for annual maintenance, facility upgrades, routine scheduled tunnel checks, etc.

User Occupancy Hours $(\mathrm{UOH})=($ Time from start of model installation in test section until model removed from test section) - (Scheduled Downtime) - (Unscheduled Downtime)

where Unscheduled Downtime includes time lost because of tunnel failures, data-system failures, power delays, etc.

Polar $=15$ data points.

\section{Appendix B: Revised WTE Goals}

\section{Technical Goals}

By 2002, the WTE provides world class subsonic, transonic, and supersonic test capability in support of NASA's goals for Global Civil Aviation, Access to Space, and Revolutionary Technology Leaps.

By 2000, the WTE provides fast, low cost, concept screening test capability across the Mach range $(0<M<20)$ to support the development of the 
next generation commercial and military aircraft and space launch vehicles.

The WTE fully integrates advanced wind tunnel testing into the next generation aircraft design processes by providing:

- an order of magnitude reduction in complete wind tunnel test cycle time by 2002 and two orders of magnitude reduction by 2010

- virtual participation by test team for entire test cycle

\section{Operations Goals}

The WTE meets all commitments to programs and customers' expectations in a timely manner while maintaining technical and operational excellence through continuous improvement of ISO 9001 certified processes in the areas of

- state of the art test techniques

- efficient test processes

- reliability centered maintenance

- value added attitude

\section{Cultural Goals}

By 1998, the WTE embraces business like practices and takes pride in providing world class testing services to its customers by

- promoting awareness of faster, better, cheaper means of providing wind tunnel services

- making the customer a welcome part of the WTE and exceeding all his expectations

- making the total experience of the customer enjoyable and intellectually stimulating

By 1998, the WTE creates a culture of excellence in wind tunnel technology and operations through creation of a "university" type environment which

trains all workers in order to

- sustain and grow all wind tunnel skills

- provide repository of all our wind tunnel knowledge

- continually develop all technical staff skills

conducts research/development of

- test technology

- new testing capability

\section{Management Goals}

The WTE management demonstrates the importance of staff through making the WTE a desirable place to work by defining and implementing realistic work expectations by April, 1998, and a true dual-career ladder for all WTE staff by September, 1998.

The WTE management demonstrates commitment to achieving the WTE goals by April, 1998, through

- alignment of resources with goals

- teaching the new way of working

- communicating and documenting the message of the WTE

The WTE encourages and participates in alliances with other wind tunnel service providers to furnish the United States with the world's finest wind tunnel services. 


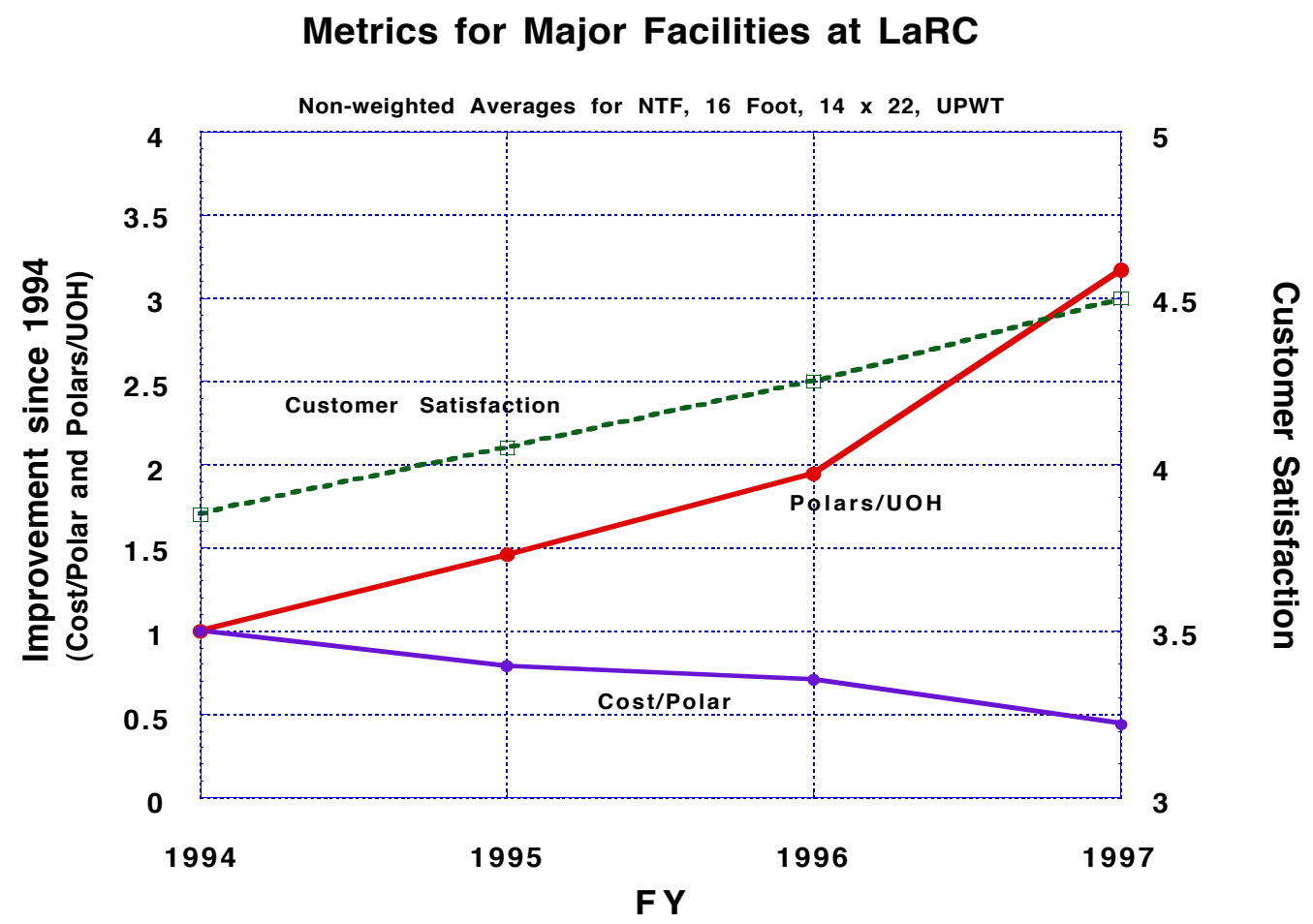

Figure 1. Productivity, Cost and Customer Satisfaction Metrics for LaRC Facilities

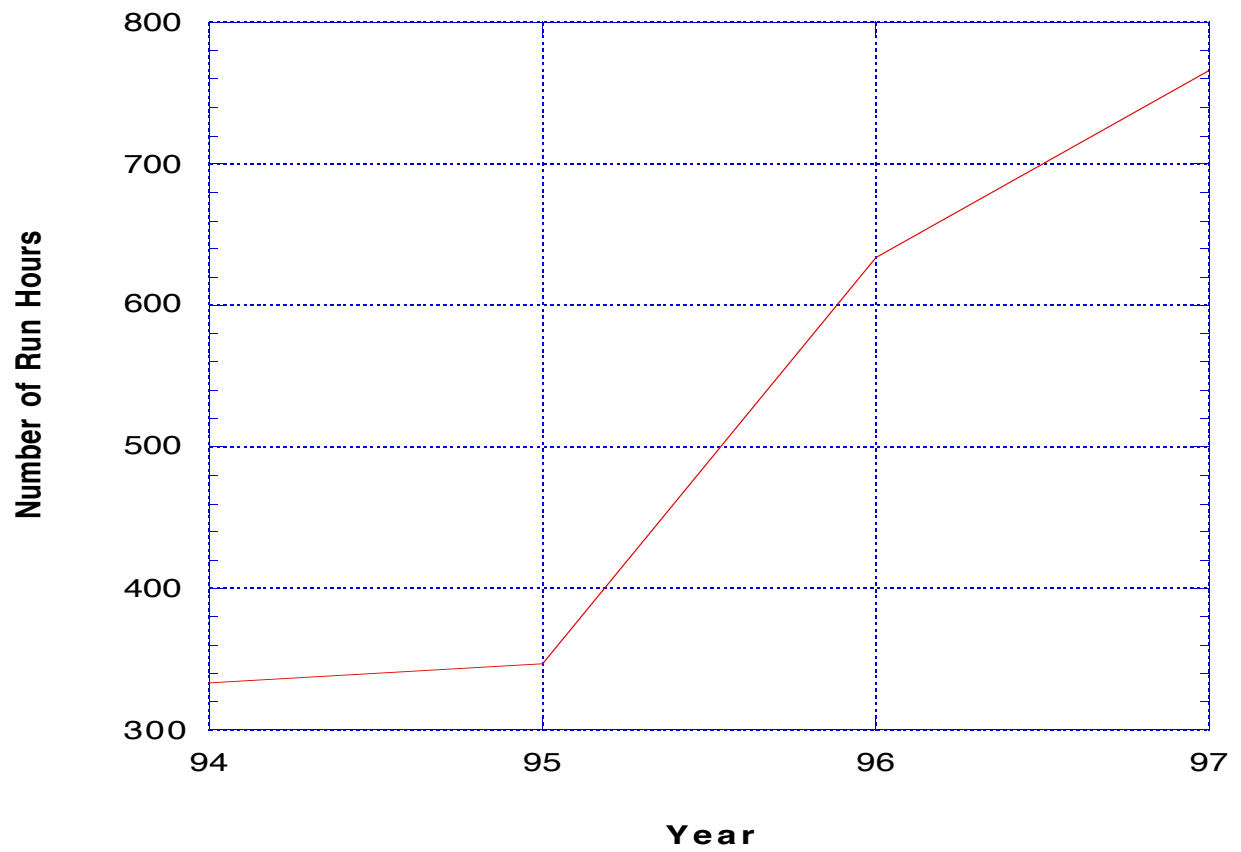

Figure 2. Number of Run Hours per Year for the 16-Foot Transonic Tunnel 


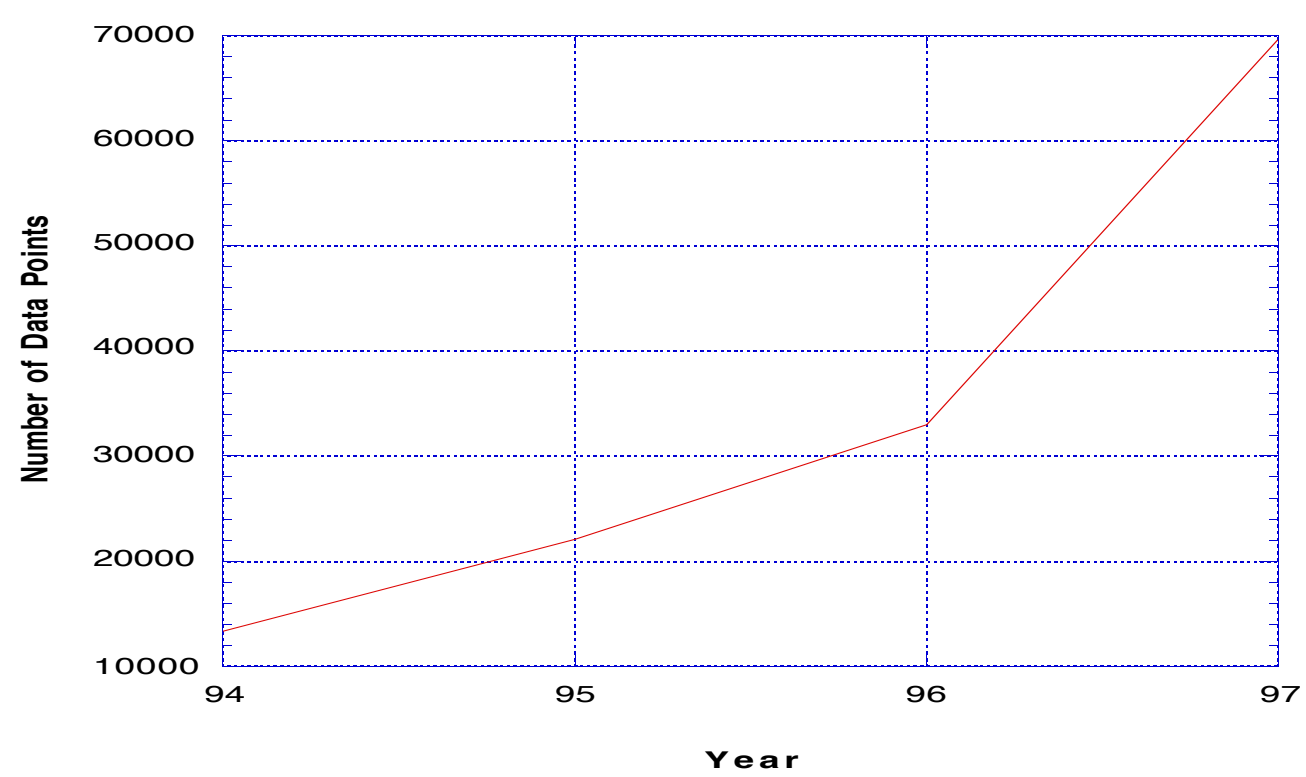

Figure 3: Number of Data Points per year at the 16-Foot Transonic Tunnel

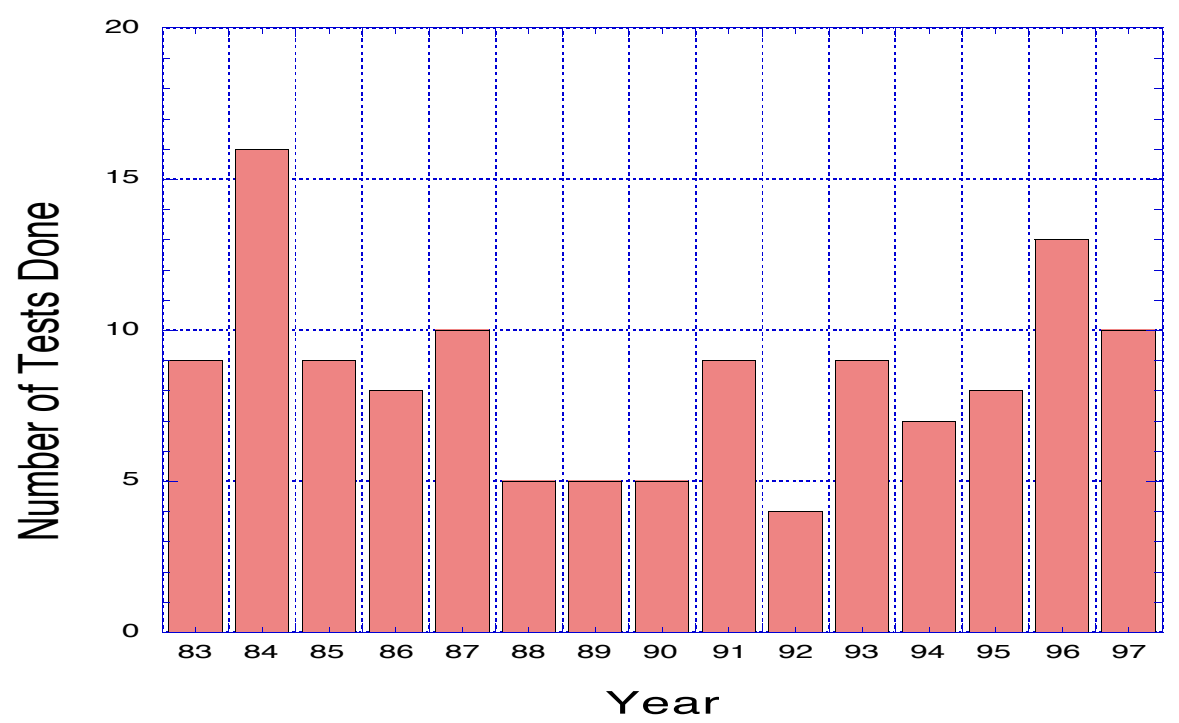

Figure 4: Current throughput of tests per year at the 16-Foot Transonic Tunnel 


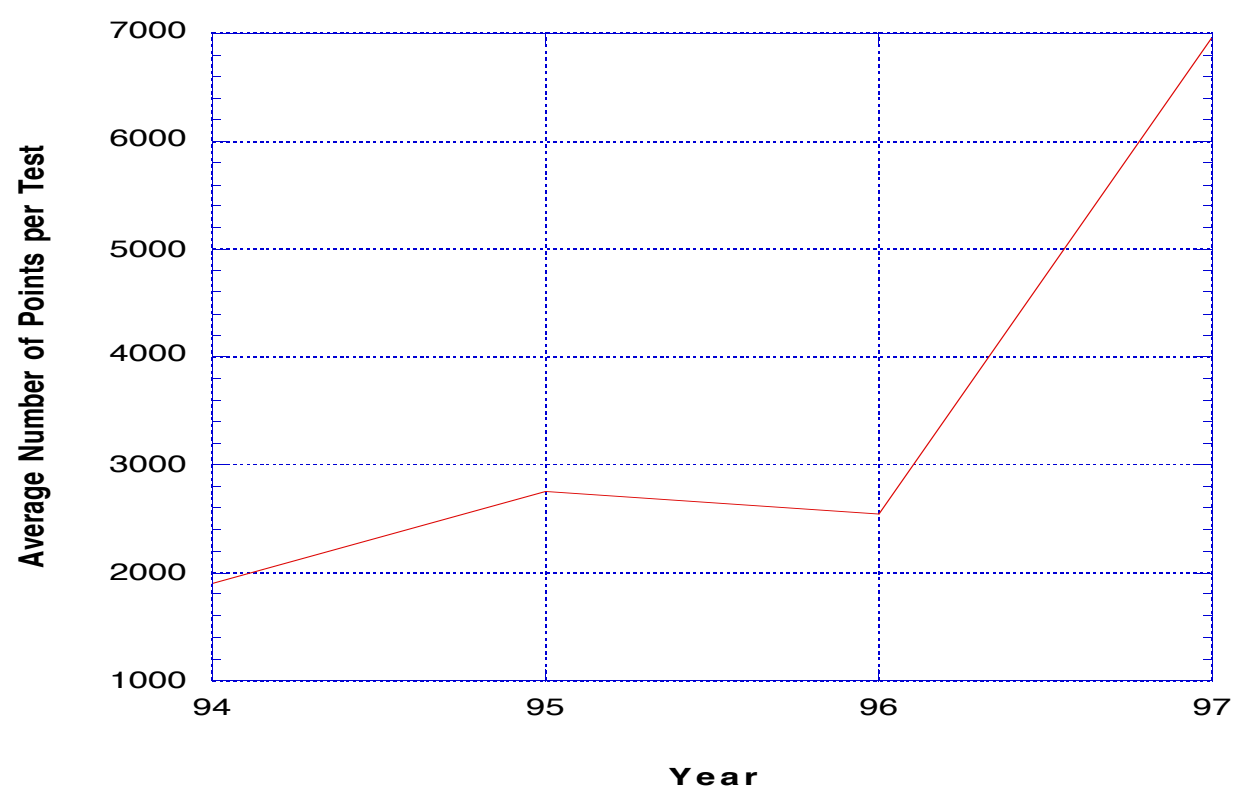

Figure 5: Average Number of points per test per year at the 16-Foot Transonic Tunnel

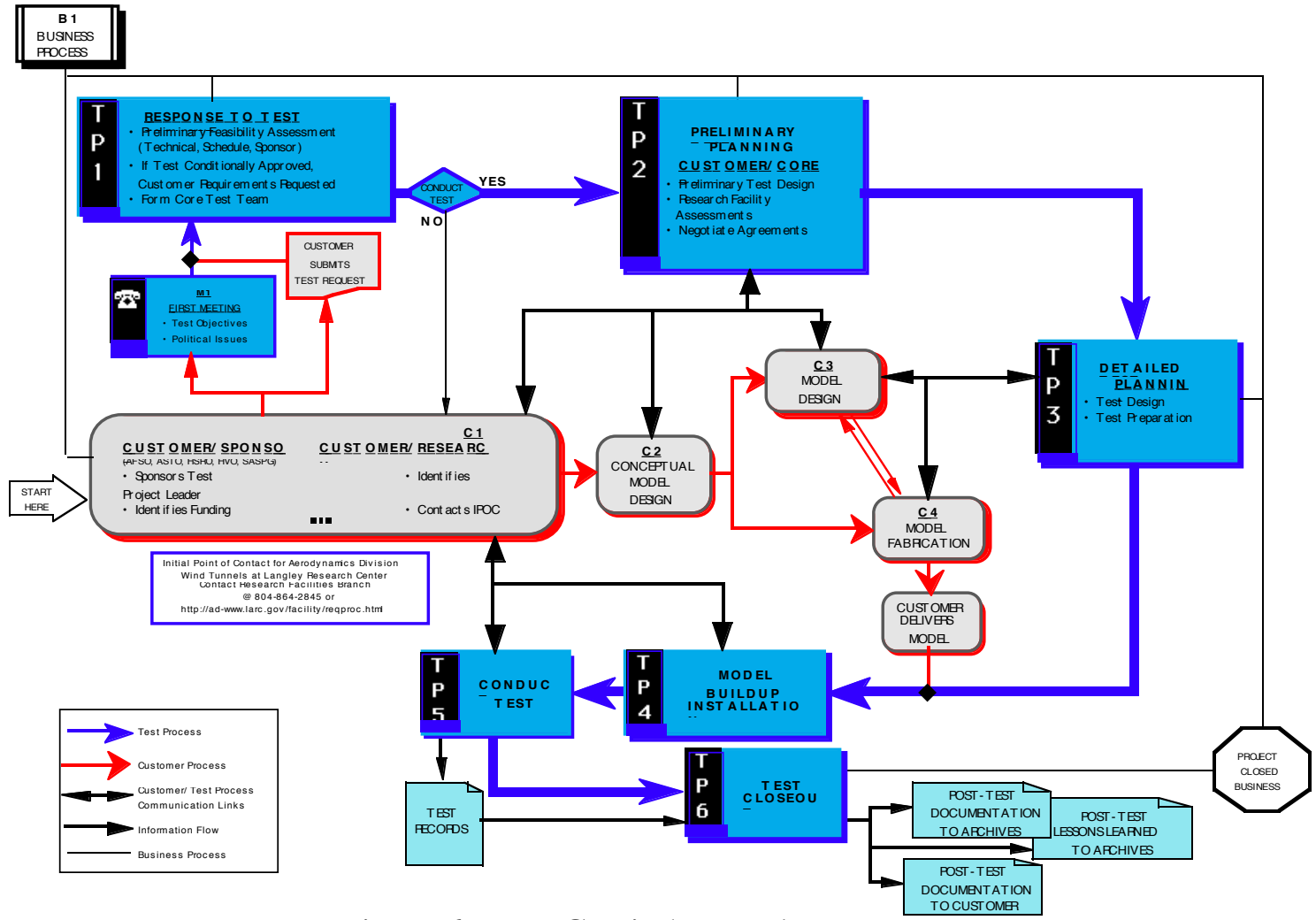

Figure 6: LaRC Wind Tunnel Test Process 

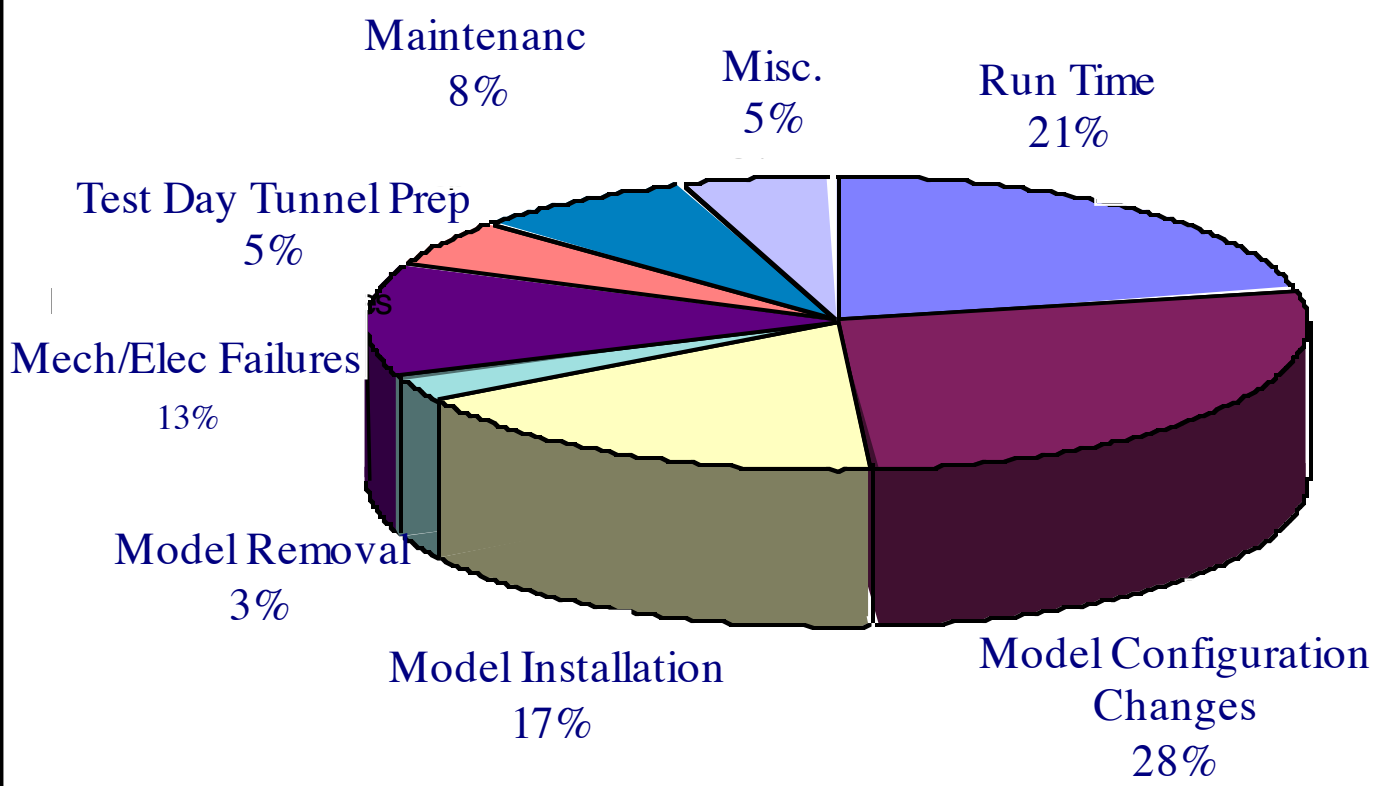

Figure 7: Wind Tunnel Time Utilization

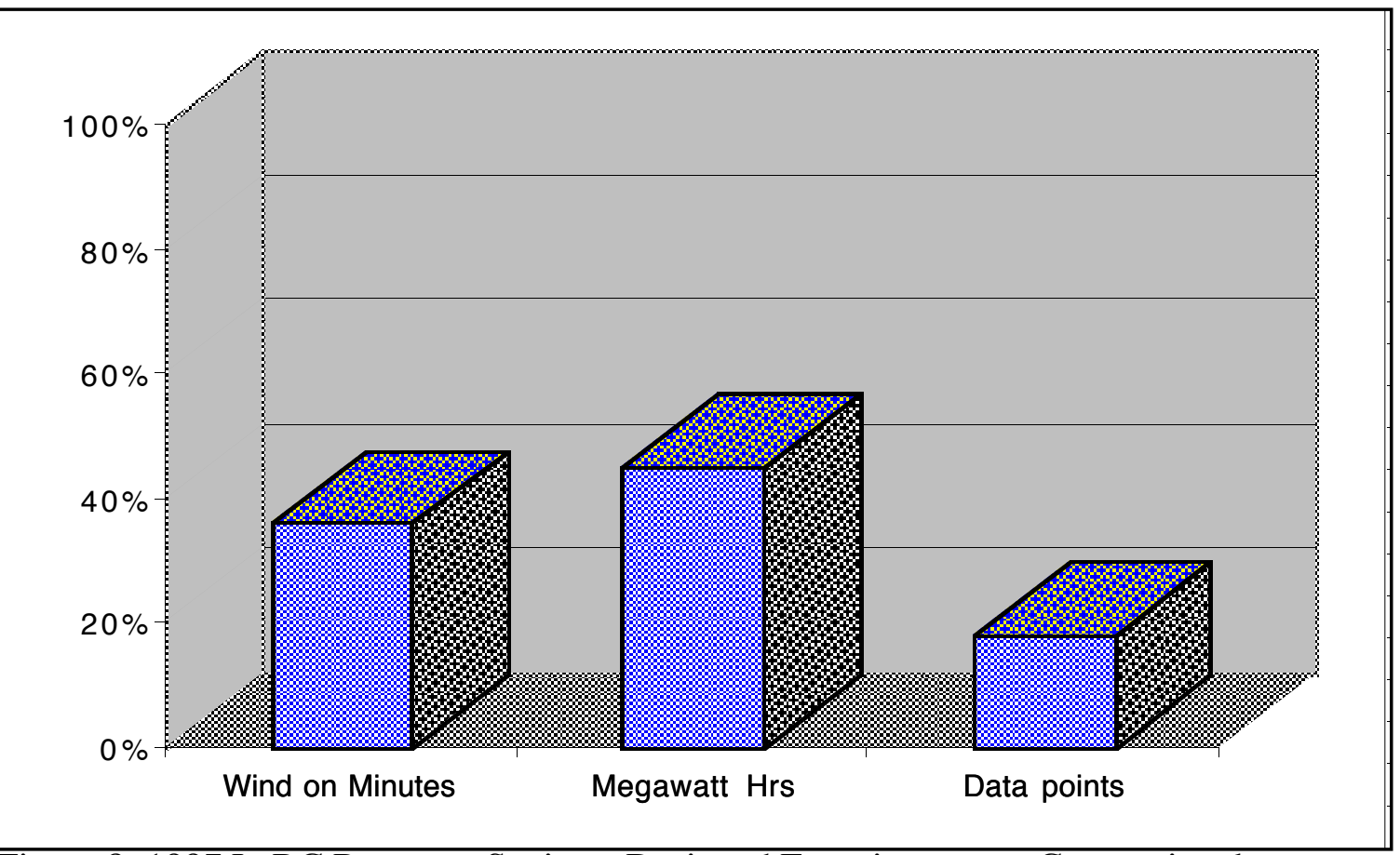

Figure 8: 1997 LaRC Resource Savings, Designed Experiments vs. Conventional Testing 


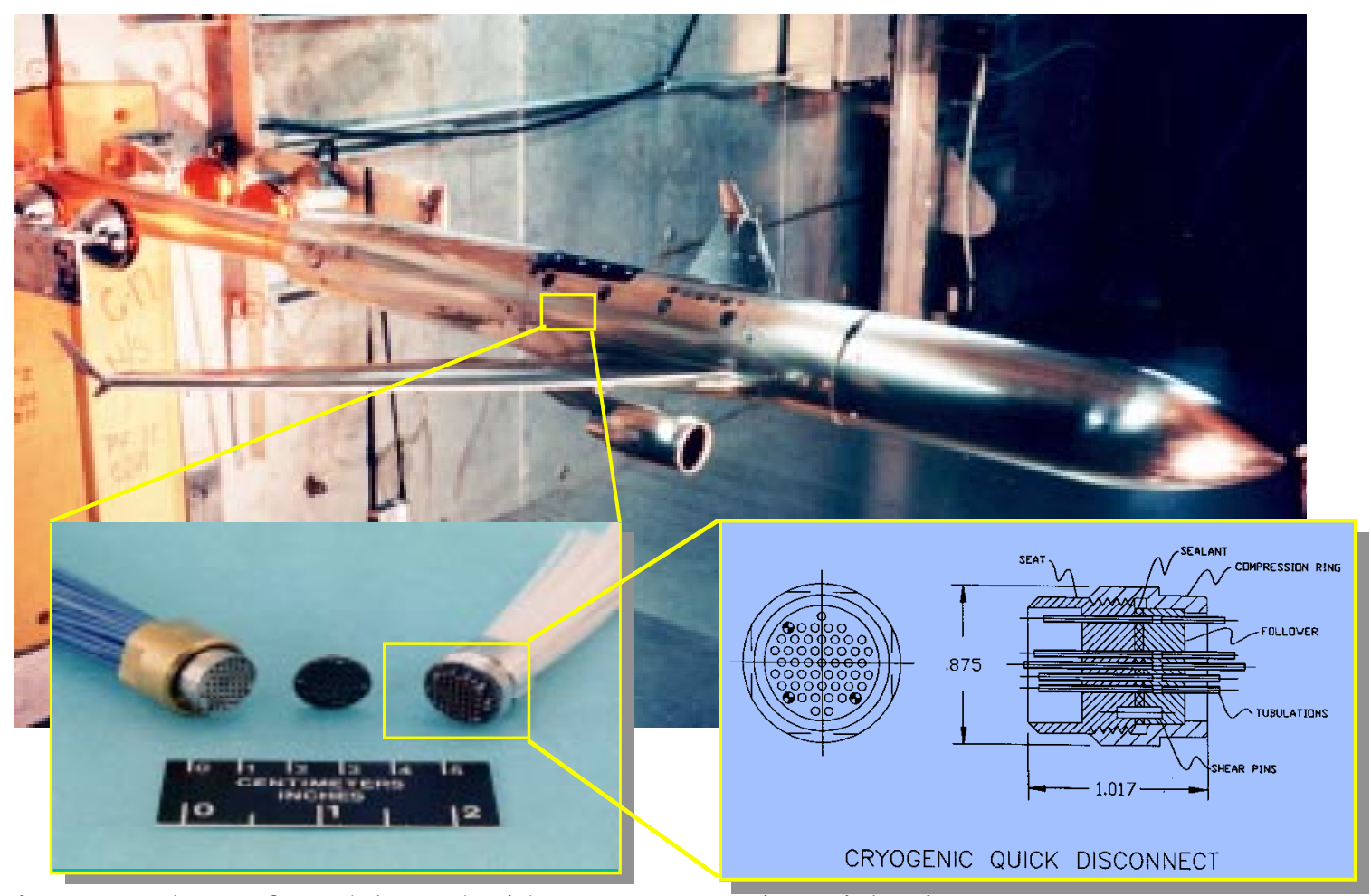

Figure 9: Photo of Model used with NTF Cryogenic Quick Disconnects

\section{On-board Instrument System}

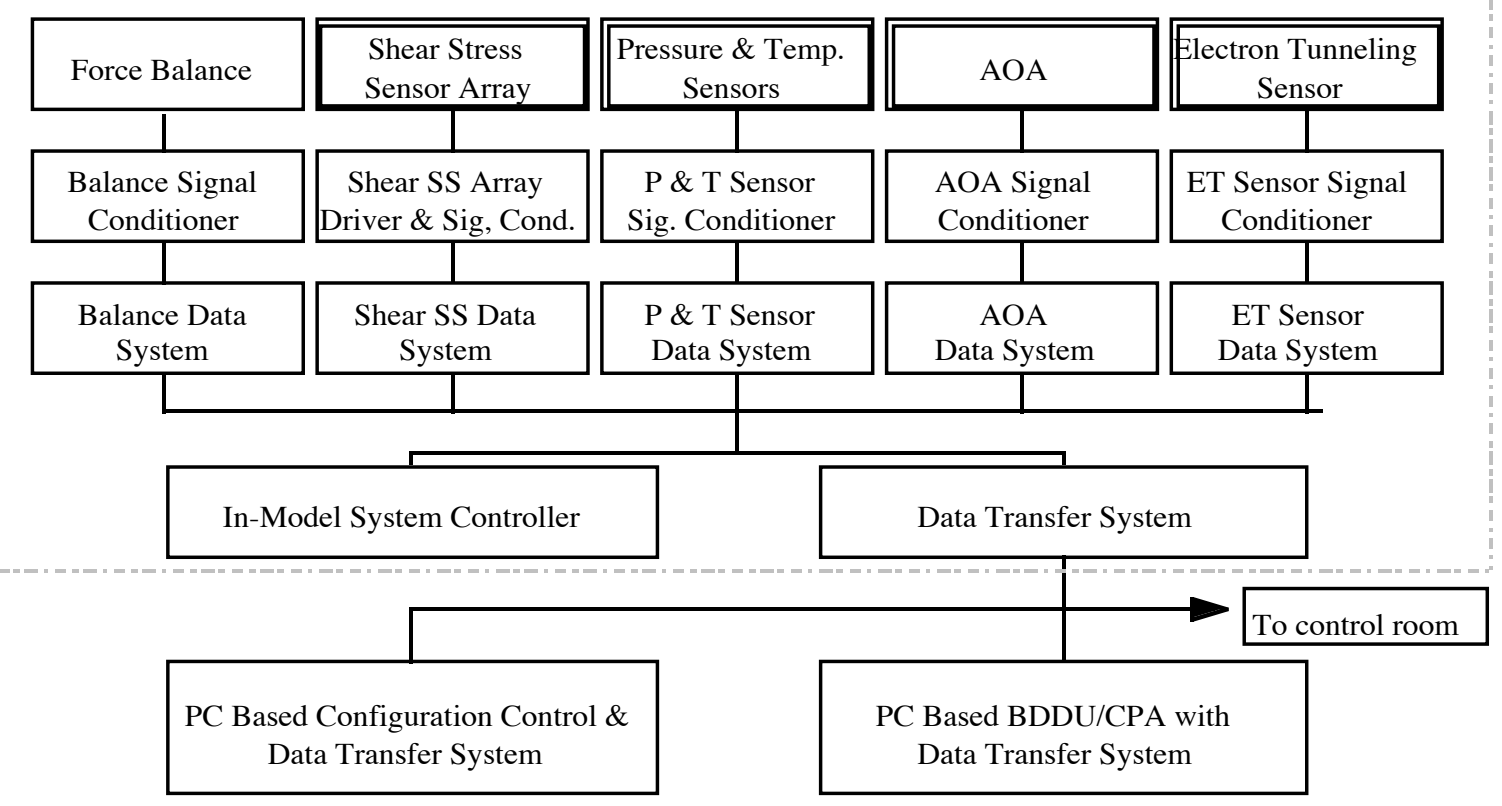

Figure 10: Block Diagram of On Board Instrumentation System 

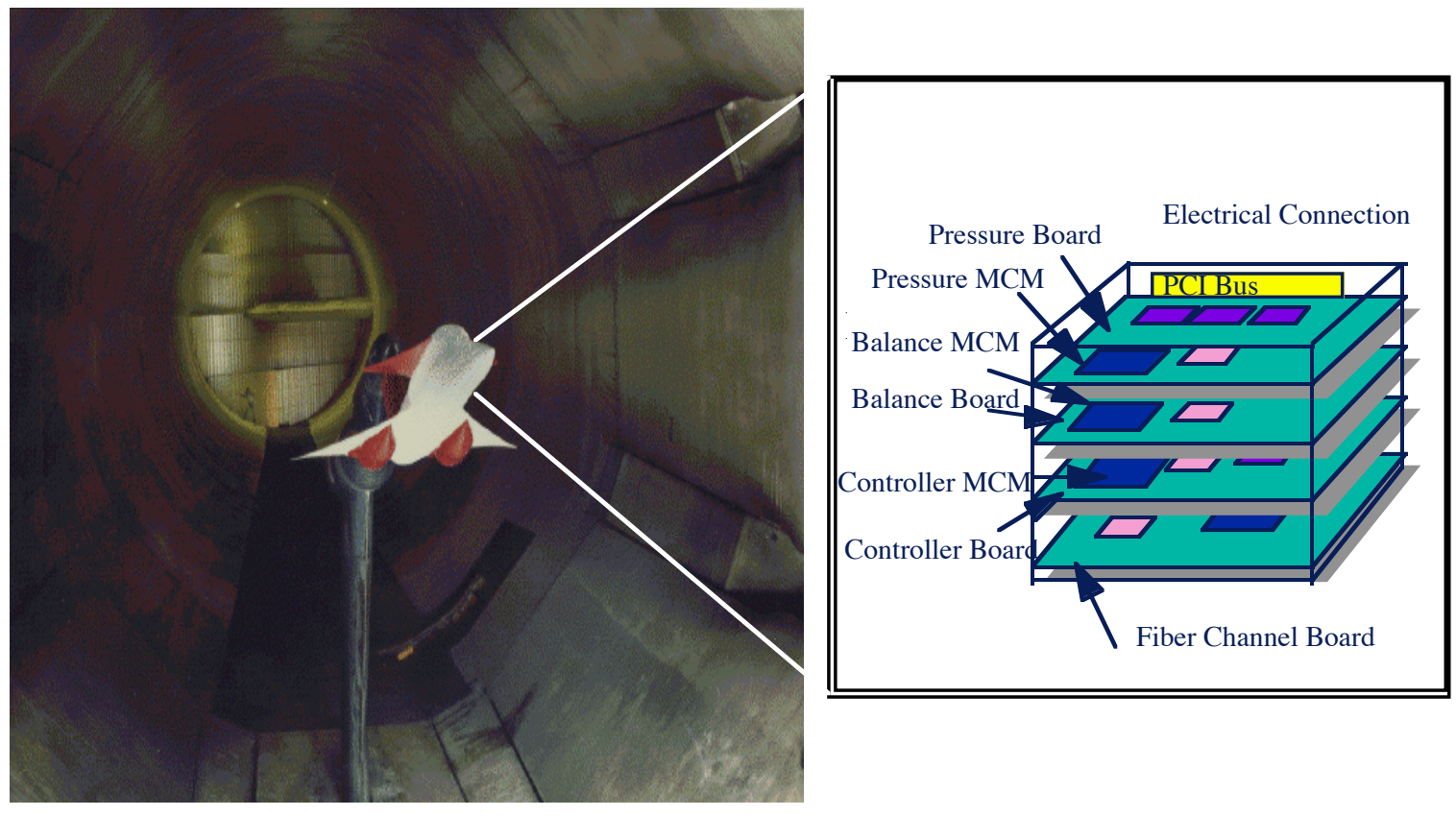

Figure 11: Photo of Model and Electronics used in 16-Foot Transonic Tunnel Telemetry Tests

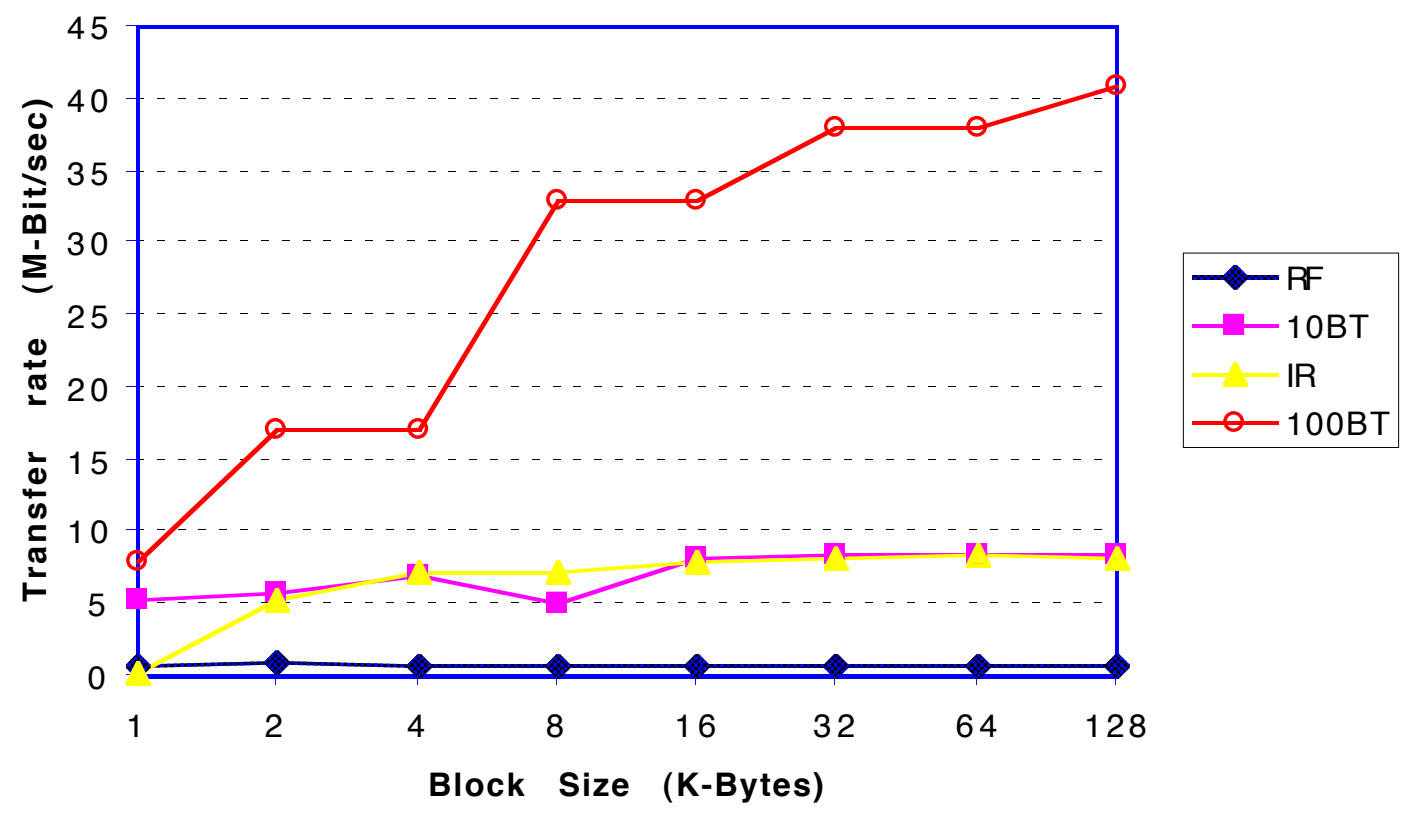

Figure 12: Data Transfer Rates (Mbit/Sec) vs. Block size(KByte) for 16-Foot Transonic Tunnel Telemetry Tests 